* Artigo convidado

** Bacharel em Direito pelo Centro Universitário de Ensino Superior do Amazonas; Especialista em Direito Público e Privado e Pós-Graduando pela Escola Superior da Magistratura do Estado do Amazonas. E-mail: nedson. brilhante@agmlogistica.com.br *** Doutor em Direito Comparado pelo Universidade de Limoges/França, Professor Adjunto da Univ. do Estado do Amazonas, do curso de Mestrado em Direito Ambiental. E-mail: vpozzetti@uea.edu.br

\section{A prescrição tributária nos tributos sujeitos a homologação *}

\author{
THE PRESCRIPTION ON TAXES SUBJECT TO \\ APPROVAL
}

\author{
Nedson Fernandes Brilhante da Silva ** \\ Valmir Cesar Pozzetti ***
}

Resumo: A prescrição tributária, objeto deste trabalho, tem como fundamento legal o artigo 174 do Código Tributário Nacional e, por conta disto, à guisa do que muitos imaginam, possui regras e natureza jurídica própria que lhe distingue da prescrição civil. A pesquisa segue como sendo descritiva quanto aos objetivos, quanto aos procedimentos bibliográfico e documental, numa abordagem qualitativa e embasamento teórico. Sendo ainda de método dedutivo se fazendo análise do conteúdo. Assim, conclui-se que toda a celeuma jurídica que envolvia o tema prescrição tributária, em tributos sujeitos a homologação, somente ficou superada a partir de 04 de agosto de 2011, oportunidade em que o Supremo Tribunal Federal proferiu decisão, nos autos do Recurso Extraordinário $\mathrm{n}^{\circ}$. 556.621, submetido ao regime de repercussão geral, firmando o entendimento de que o prazo prescricional quinquenal tão somente deve ser aplicado às ações ajuizadas após a entrada em vigor da LC n. 118/2005, e não aos valores indevidamente recolhidos antes de sua vigência da referida lei, conforme o STJ vinha concluindo.

Palavras-Chave: Prescrição Tributária; Tributos sujeitos a homologação; Jurisprudência.

Abstract: The tax prescription, the object of this paper, has the legal basis in the article 174 of National Tax Code - CTN and has different rules and legal nature of the privative prescription. The methodology can be classified as been descriptive, documental and bibliographic, theoretical and deductive. Thus, we can conclude that all the juridical argue involving this issue only was solved after Brazilian Supreme Court to issue your decision confirming that the prescription tax of five years only can be used to the action filed after the force of the complementary law number $118 / 05$ and not to the improperly values paid before the complementary law 118/05 forces.

Keywords: Tax Prescription; The approval tax subjects; Jurisprudence. 


\section{INTRODUÇÃO}

Ab initio, pode-se dizer que Estado teve a família como sendo o seu principal marco constitutivo, porque foi através da evolução familiar que a sociedade pôde se estruturar e formar o Estado moderno que se vive hoje.

Nesse sentido, pode-se dizer que o Estado nada mais é do que a forma que a família encontrou para tentar alcançar, coletiva e organizadamente, respostas às suas necessidades e anseios, existentes outrora, na forma individual.

É, exatamente, em nome dessas necessidades que o Estado impõe a seus súditos o dever de pagar tributo. Ou seja: a imposição tributária nada mais é do que um direito soberano que o Estado tem de, em nome do bem comum, criar e cobrar tributos, para tutelar a paz e a organização do Estado.

Destarte, o Estado não pode se armar de seu poder soberano para instituir e cobrar tributo de forma arbitrária. É necessário que a lei imponha limites a tal poder, sob pena de ferir diversos princípios constitucionais, como o da legalidade, dignidade da pessoa humana e segurança jurídica. E, é, exatamente, por conta dessa necessidade de se limitar o poder do Estado, visando dar segurança jurídica nas suas relações para com os contribuintes, que surge a prescrição tributária.

Assim, a prescrição nada mais é do que fenômeno extintivo de uma ação ajuizável, em razão da inércia de seu titular, durante determinado espaço de tempo que a lei estabeleceu para esse fim. O silêncio da relação jurídica durante um espaço de tempo determinado pela lei significa a perda da ação atribuída a um direito e corresponde à capacidade defensiva. Assim, têm a prescrição interesse público, visando à harmonia social e ao equilíbrio das relações jurídicas tuteladas pela ordem pública.

\section{IMPOSIÇÃO TRIBUTARIA}

Segundo Martins, "o Estado surgiu da evolução familiar, passou pelo feudalismo, monarquia e chegou a sua conformação atual, onde se encontra amparado pela lei”. (2004, p.32).

Neste sentido, Martins conceitua o Estado como sendo "a sociedade política e juridicamente organizada, dotada de soberania, dentro de um território, sobe um governo, para realização do bem comum do povo". (2004, p.32).

Há três componentes básicos inerentes a qualquer conceito de Estado: a) povo, que é o componente humano; b) território, que é o elemento material ou físico; e: c) governo, que é a organização necessária para o exercício do poder político. 
Além, dos três componentes, acima dispostos, existe um quarto que também merece destaque, que é a Soberania. Conforme leciona Martins, a "Soberania é o poder de organizar-se juridicamente e de fazer valer dentro de seu território a universalidade de suas decisões nos limites dos fins éticos de convivência". (2004, p.33).

A soberania é um importante elemento constitutivo do Estado, porque é em nome da soberania que o Estado exige que seus súditos lhe transfiram parte de seus rendimentos, visando custear os fins de que necessita. Assim, pode-se concluir que, conforme Danari, "o poder tributário - entendido como a faculdade que possui o Estado de impor tributos - nada mais é do que um atributo da soberania estatal". (2002, p.37).

O tributo, por ser um atributo de soberania do Estado, é irrenunciável e indelegável. Ou seja: é intransferível a outrem, caso não utilizado.

Destarte, não se pode dizer que o Estado tem apenas o poder tributar, pois esse poder de tributar envolve uma relação jurídica entre ele e o contribuinte. Há direitos e deveres, tanto do Estado, como dos contribuintes. Segundo Martins, "as normas a serem aplicadas dizem respeito tanto ao Estado como aos contribuintes". (2004, p.34).

Por conta disso, é que há necessidade da lei estabelecer limites ao poder de tributar do Estado, pois, do contrário, este tributaria toda a riqueza do contribuinte ou parte dela.

\subsection{Conceito de Tributo}

Conforme leciona Danari, “o nome 'tributo' designa, genericamente, as imposições legais instituídas, pelo Estado, para obtenção de recursos financeiros. (2002, p.33).

A Constituição Federal brasileira não define tributo. A definição legal de tributo é encontrada no artigo $3^{\circ}$ do Código Tributário Nacional:

Art. $3^{\circ}$. Tributo é toda prestação pecuniária compulsória, em moeda ou cujo valor nela se possa exprimir, que não constitua sanção de ato ilícito, instituída em lei e cobrada mediante atividade administrativa plenamente vinculada".

Neste sentido Martins esclarece que "Tributo é uma prestação de dar, de pagar. Não se trata de obrigação de fazer ou não fazer. Tributo é o objeto da 
relação tributária e tem por objetivo carrear para os cofres do Estado meios financeiros para a satisfação das necessidades da coletividade". (2004, p.99).

A partir de sua definição legal, podem-se ser inferidas cinco características básicas, peculiar a qualquer espécie:

a) Prestação pecuniária: que nada mais é do que o dever de se pagar o tributo em dinheiro, não se admitindo, em regra geral, que tal pagamento seja feito de outra forma. Exceto quando expressamente autorizado por lei, como é o que ocorre no artigo 156, XI, do CTN, que autoriza o pagamento efetuado através da dação de bens imóveis;

b) Compulsoriedade: é irrelevante a manifestação de vontade das partes para constituição do crédito;

c) Caráter sancionatório: Em regra, a exigibilidade do tributo não pode ser feita levando-se em consideração a ocorrência de um ato ilícito cometido pelo contribuinte, não pode ser uma punição.

d) Instituição por lei (formal e material): Ou seja, via de regra, a criação de um novo tributo é feito através de lei complementar. Não obstante a isso, há casos em que a criação de um tributo só poderá ser feita através de uma lei complementar, como é o caso do empréstimo compulsório mencionado no artigo 148 da $\mathrm{CF} / 88$.

e) Cobrança feita através de uma atividade vinculada. Para cobrar o tributo, o Estado deve lançar em seus controles internos o crédito tributário, conforme determina a legislação, através do lançamento, após a pratica do fato gerador, pelo contribuinte; só assim, o crédito será legítimo. Assim, não há que se falar em juízo de "oportunidade e conveniência" a ser realizado pelo administrador, como acontece nas atividades e atos discricionários. Portanto, ocorrendo o fato gerador a Administração realiza o lançamento constituindo seu crédito tributário, o que obriga o contribuinte a pagar o tributo, compulsoriamente.

\subsection{Exigibilidade do Tributo}

De forma geral, pode-se dizer que um tributo somente será exigível se atender as normas insculpidas no artigo 150, caput e incisos I e III da Constituição Federal de 1.988. Ou seja, só poderá ser exigido: se tal tributo for instituído por lei, se não retroagir para prejudicar o contribuinte e se respeitar o prazo anual e nonagésimal para produção de seus efeitos.

Não obstante a isso, casos há em que a própria Constituição Federal de 1988 autoriza a criação de um tributo, sem que seja necessário respeitar as 
regras mencionadas no artigo 150, inciso I e III, como ocorrem com os tributos em que se aplica a regra do $\S 1^{\circ}$ deste artigo.

\section{PRESCRIÇÃO TRIBUTÁRIA}

A prescrição é um instituto que se relaciona com o direito de ação. Historicamente, a prescrição surgiu no sistema formulário do processo romano, como exceção. O pretor, ao criar uma espécie de ação, previa um prazo dentro do qual o direito de interpô-la deveria ser exercido, sob pena de prescrição. Esta, assim, constituía um instrumento contra o titular do direito que deixou de protegê-lo por meio da ação; ou seja, pela sua inércia em não exercer o direito de ação. Pela prescrição, portanto, o que se atinge é a ação, ou o "direito de ação".

Conforme nos relata Martins, "no Direito Romano indicavam-se três fontes como fundamentos para a prescrição: a) para a não-fixação de relações jurídicas incertas; b) visando castigar a negligência; c) de sempre haver interesse público". (2004, p.204).

Ainda segundo Martins, "antes da vigência do CTN, o inciso VI do $§ 10^{\circ}$ do artigo 178 do Código Civil de 1916 regulava a prescrição tributária, determinando que "as dividas passivas da União, dos Estados e dos Municípios, e bem assim toda e qualquer ação contra a Fazenda Federal, Estadual ou Municipal, prescreviam em cinco anos”. (2004, p.204).

\subsection{Conceito de Prescrição}

A palavra "prescrição"tem origem latina e, segundo Martins, vem do "Praescripto (do verbo praescribero, de prae + scribero), escrever antes do começo, lembra-se a parte preliminar (escrita antes) da fórmula em que o pretor romano determinava, ao juiz, absolvição do réu, caso estivesse esgotado o prazo de ação. Uma vez extinto o lapso de tempo para uso da ação, cabia a exceção de prescrição temporal, em razão da falta do exercício da ação. Isso se dava no direito pretoriano, pois no direito romano antigo as ações eram perpétuas ou inatingíveis. Com a evolução do conceito de prescrição, esta passou a significar a extinção da ação pela expiração do prazo de sua duração (exercício tardio da ação). Há necessidade de se ter certeza e estabilidade nas relações jurídicas, respeitando o direito adquirido, de acordo com um determinado espaço de tempo. $\mathrm{O}$ interesse público não se compadece com a incerteza das relações jurídicas, 
criadoras de desarmonia e estabilidade, e que é protegida quando se baixam normas de prescrição, evitando que se eternizem, sem solução, as situações duvidosas ou controvertidas. As pretensões tardias são inadmissíveis, trazendo incertezas nas relações humanas. Trata-se, pois, de um instituto de ordem jurídica que estabiliza as relações jurídicas. Na ordem pública, os fatos que por muito tempo não sofrem contestação adquirem a presunção de se acharem elaborados e terem gerado direito, pelo que não convém aos interesses sociais a modificação de tal situação". (2004, p.204).

Clóvis Bevilácqua, citado por Martins, define prescrição como a "perda da ação atribuída a um direito, e de toda a sua capacidade defensiva, em consequência do não-uso delas, durante um determinado espaço de tempo". (2004, p.205)

Importante destacar que, para que haja prescrição é necessário o preenchimento dos seguintes pressupostos: a) existência de um direito material da parte a uma prestação (ação ou omissão) a ser cumprida por outrem; b) descumprimento da prestação por parte do obrigado, surgindo, assim, o poder para o credor exigir o cumprimento da obrigação na via judicial; c) inércia do titular da pretensão em fazê-la valer em juízo, no prazo determinado em lei.

Assim, representa a prescrição o fenômeno extintivo de uma ação ajuizável, em razão da inércia de seu titular, durante determinado espaço de tempo que a lei estabeleceu para esse fim. O silêncio da relação jurídica durante um espaço de tempo determinado pela lei significa a perda da ação atribuída a um direito e corresponde à capacidade defensiva. Tem a prescrição interesse público visando à harmonia social e ao equilíbrio das relações jurídicas tuteladas pela ordem pública.

\subsection{Principais distinções existentes entre Prescrição Civil e Tributária}

A principal distinção existente entre prescrição civil e tributária se dá em relação a seus universos de atuação, vez que a prescrição civil se presta a regular, de forma taxativa, as relações patrimoniais existentes entre particulares, ao passo que a prescrição tributária se presta a disciplinar as relações tributárias existentes entre a Fazenda Pública e o contribuinte. Também, destaca-se, que a prescrição civil é regida por regras de direito privado enquanto que a prescrição tributaria é regida por regras de direito público.

Outro ponto de distinção existente prescrição civil e tributária é a que versa sobre o termo inicial para a contagem do prazo prescricional. Na prescrição 
civil começa a correr a partir do momento em que há violação ou lesão ao direito do sujeito e, na prescrição tributária somente começa a correr a partir do momento em que há a constituição definitiva do crédito tributário, conforme dispõe o artigo 174, caput, do CTN.

Ressalte-se que a constituição definitiva do crédito tributário somente é aferida a partir do momento em que há o exaurimento de todas as possibilidades de contestação na via administrativa.

Por fim, o último ponto de distinção merecedor de destaque é o que versa sobre a possibilidade do sujeito passivo lançar mão da ação de indébito, para restituir pagamento feito sobre um crédito prescrito, que na seara tributária é plenamente possível, face ao disposto no artigo 156, caput, e inciso V, combinado com o artigo 113, caput, e $\S 1^{\circ}$, ambos do CTN e que na seara privada é impossível, face ao disposto no artigo 882 do CCB vigente, que diz que "veda a utilização de ação repetitória para solver dívida prescrita, ou cumprir obrigação juridicamente inexigível".

Pelo exposto, conclui-se que a natureza jurídica da prescrição tributária é de caducidade e que a regra do artigo 882 do CCB definitivamente não se aplica na seara tributária.

\section{PRESCRIÇÃO NOS TRIBUTOS SUJEITOS À HOMOLOGAÇÃO}

Conforme leciona Danari, "o crédito tributário pode derivar de um procedimento não impositivo que o Código Tributário Nacional, em seu artigo 150, denomina lançamento por homologação". (2002, p.212).

Dispõe o artigo $150, \S 1^{\circ}$ do CTN que o pagamento antecipado pelo obrigado extingue o crédito tributário, sob condição resolutória da ulterior homologação do lançamento.

Se a lei não fixar prazo à homologação, será ele de cinco anos, a contar da ocorrência do fato gerador. Expirando esse prazo sem que a Fazenda Pública se tenha pronunciado, considera-se homologado o lançamento e definitivamente extinto o crédito, salvo se comprovada a ocorrência de dolo, fraude ou simulação, conforme disposto no $\S 4^{\circ}$ do artigo 150 do CTN.

O pagamento antecipado é realizado nos tributos lançados por homologação, em que o sujeito passivo antecipa o recolhimento do tributo e espera a homologação pelo fisco. Conforme Martins, "crédito tributário não fica extinto com o pagamento, mas com a homologação". (2004, p.208). 


\subsection{Conceito de homologação tributaria}

O fundamento legal do instituto da homologação é encontrado no artigo 150 do Código Tributário Nacional, que assim estabelece:

Art. 150. O lançamento por homologação, que ocorre quanto aos tributos, cuja legislação atribua ao sujeito passivo o dever de antecipar o pagamento sem prévio exame da autoridade administrativa, opera-se pelo ato em que a referida autoridade, tomando conhecimento da atividade assim exercida pelo obrigado, expressamente a homologa.

Assim, tributo lançado por homologação, conforme relata machado, "é aquele em que a legislação atribui ao sujeito passivo o dever de antecipar o pagamento, antes mesmo do exame do ente tributante. A autoridade fazendária, após tomar conhecimento da apuração feita pelo sujeito passivo, deve homologar, ou não, o resultado do procedimento". (2007, p.204).

Ou seja: nos tributos sujeitos a lançamento por homologação, o sujeito passivo se antecipa à Fazenda Pública, entrega ao Fisco a declaração devida, informando o valor que entende devido dos tributos, e procede à quitação da exação, aguardando o procedimento homologatório expresso ou tácito.

São espécies de tributos sujeitos à homologação: o Imposto de Renda, Imposto sobre Produtos Industrializados, Imposto sobre Circulação de Mercadorias e Serviços e Programa de Integração Social.

\subsection{Visão do Superior Tribunal de Justiça}

Uma vez já exposto os principais fundamentos da prescrição tributária e a visão doutrinária, é importante verificarmos o posicionamento que os Tribunais Superiores brasileiros tem tomado para resolver a questão envolvendo a prescrição tributária nos tributos sujeitos a homologação pela Fazenda Pública.

Pode-se dizer que o tema prescrição tributária nos Tribunais Superiores brasileiro está dividido em dois momentos: Prescrição Tributária antes do Advento da Lei Complementar 118/05 e Prescrição Tributária após o advento da Lei Complementar 118/05.

Antes do advento da Lei Complementar 118, que ocorreu em 09 de Fevereiro de 2005, o Superior Tribunal de Justiça adotava em suas decisões, com base em uma interpretação conjunta dos artigos $150, \S 4^{\circ}$ e 168 , I, do 
Código Tributário Nacional, o entendimento segundo o qual a repetição de indébito, no caso de tributos submetidos a lançamento por homologação, poderia ser pleiteada em até 10 anos.

Tal construção jurisprudencial do Superior Tribunal de Justiça foi firmada para fins de dirimir a dúvida que pairava sobre o marco inicial de contagem do prazo prescricional nos tributos sujeitos a homologação, que para alguns deveria iniciar logo após o pagamento indevidamente feito pelo contribuinte e que, para outros, somente deveria ser iniciado cinco anos após o pagamento do crédito indevido, visto que a extinção do crédito, nestes casos, somente se daria com a homologação, expressa ou tácita, do procedimento efetuado pelo contribuinte, sendo que neste caso o prazo prescricional somente expiraria depois de transpassados o lapso temporal de 10 anos do pagamento do crédito indevido.

Neste sentido, veja-se o teor dos Embargos de Divergência em Recurso Especial $n^{\circ}$ 262475/DF, STJ, 2003:

EMBARGOS DE DIVERGÊNCIA. TRIBUTÁRIO. REPETIÇÃO DE INDÉBITO. IMPOSTO DE RENDA RETIDO NA FONTE. HIPÓTESE DE INCIDÊNCIA COMPLEXA. TRIBUTO SUJEITO A LANÇAMENTO POR HOMOLOGAÇÃO. PRESCRIÇÃO. ERESPN. 289.398D DF.

$\mathrm{Na}$ assentada de 27 de novembro de 2002, esta Primeira Seção desta Corte Superior de Justiça firmou o entendimento, segundo o qual, na restituição do imposto de renda descontado na fonte, incide a regra geral do prazo prescricional aplicada aos tributos sujeitos à homologação, no sentido de que a extinção do direito de pleitear a restituição ocorrerá após 05 (cinco) anos, contados do fato gerador, acrescidos de mais 05 (cinco) anos da homologação (EREsp n. 289.398D DF, rel. o subscritor deste).

Assim, fica claro que o entendimento adotado pelo Superior Tribunal de Justiça foi no sentido exclusivo de resolver a celeuma jurídica que existia em relação ao termo inicial para a contagem do prazo prescricional, a ser adotada para fins de declaração da prescrição do crédito tributário sujeito a homologação, nas ações de repetição de indébitos.

Desse modo, ficou pacificado que a extinção do crédito tributário só se efetivaria, quando não expressamente homologado, após o decurso do prazo legal da homologação tácita, podendo perfazer um prazo total de até 10 (dez) anos a partir do momento em que surge o fato gerador do tributo, atribuindo-se, assim, a natureza de cláusula suspensiva ao pagamento antecipado, postergando seus efeitos jurídicos. 
No entanto, a decisão do STJ serviu para dar cabo aos efeitos do problema e não à sua causa, visto que a causa raiz residia na obscuridade do inciso I do artigo 168 do CTN, que em sua redação não estabelecia o termo inicial para a contagem do prazo prescricional. Some-se a isso, ainda, o grande prejuízo que o Fisco teria com o advento da decisão tomada pelo STJ, visto que, em face dela, o mesmo estaria obrigado a dar seguimento a milhares de ações de indébito que entendia já estarem prescritas.

Decidiu-se então, via lei complementar 118/05, fixar o termo inicial para contagem do prazo prescricional, conforme pode-se inferir da redação do artigo $3^{\circ}$ da Lei Complementar, in verbis:

Art. $3^{\circ}$. Para efeito da de interpretação do inciso I do art. 168 do CTN, a extinção do crédito tributário ocorre, no caso de tributo sujeito a homologação, no momento do pagamento antecipado de que trata o $\S 1^{\circ}$ do artigo 150 da referida lei.

Assim, o que antes se mostrava desfavorável aos interesses da Fazenda Pública mudou, visto que com a nova medida, fixação do termo inicial de contagem do prazo prescricional a partir do momento do pagamento indevido, o prazo total prescricional reduziu-se para 5 (cinco) anos e não mais 10 ez0 anos, como o STJ vinha decidindo.

Ocorre que a mesma lei complementar 118/05, insculpida sob a égide de ser uma lei meramente interpretativa, trouxe no bojo do seu artigo $4^{\circ}$, norma determinando a retroatividade dos efeitos da lei, para atingir todos os processos ainda pendentes até o momento de sua vigência.

A partir daí, o tema prescrição tributária sobre tributos sujeitos a homologação, que aparentava já estar pacificado pelo STJ, voltou a ganhar força naquele Tribunal, visto que seus membros passaram a divergir em suas decisões acerca da natureza jurídica da Lei Complementar 118/05, ao que uns afirmavam ser a lei meramente interpretativa e que outros afirmavam ser modificativa.

Tal discussão se mostrou necessária, visto que o bem maior que estava em jogo não era tão somente saber se a lei era puramente interpretativa ou modificativa, mas, sim, saber qual seria o âmbito temporal de incidência da norma, já que em sendo lei interpretativa seus efeitos retroagiriam para alcançar os processos ainda pendentes, conforme interesse da Fazenda Pública. 
Assim, após muitas discussões e decisões controvertidas acerca da matéria, o STJ firmou entendimento de que a Lei Complementar $n^{\circ}$. 118/2005 só incidiria nos casos em que o pagamento indevido fosse realizado após a sua vigência, afastando de vez a ideia da Lei Complementar 118/05 ser meramente interpretativa, conforme pode-se inferir da decisão proferida nos Embargos de Divergência em Recurso Especial no 644736 (STJ, 2005).

Na prática, o STJ, ao declarar que a lei complementar não era interpretativa, mantinha a força da interpretação que ele próprio anteriormente consagrara.

No entanto, para a defesa e manutenção de seu posicionamento, o STJ necessitou lançar mão de normas constitucionais hierarquicamente superiores, por entender que o preceito estabelecido no artigo $3^{\circ}$ e $4^{\circ}$ da Lei Complementar 118/05, violava os princípios constitucionais da separação dos poderes, (artigo $2^{\circ} \mathrm{da} \mathrm{CF} / 88$ ), o direito adquirido, o ato jurídico perfeito e a coisa julgada (artigo $5^{\circ}$, inciso XXXVI da CF/88). Logo, como o STJ fundamentou sua decisão em normas e princípios constitucionais, a questão chegou ao STF.

\subsection{Visão do Supremo Tribunal Federal}

No STF a decisão que pôs fim a divergência que cercava o tema foi proferida nos autos do Recurso Extraordinário ${ }^{\circ}$. 556.621/RS, submetido ao regime de repercussão geral, ocorrido em 04 de agosto de 2011.

Em sua decisão, a Suprema Corte pugnou por ratificar o posicionamento anteriormente já adotado pelo STJ acerca da ilegitimidade da aplicação retroativa do lustro prescricional para o pleito de repetição do indébito tributário lançado por homologação.

Não obstante a isso, firmou o entendimento de que o prazo prescricional quinquenal tão somente deve ser aplicado às ações ajuizadas após a entrada em vigor da $\mathrm{LC}^{\circ}{ }^{\circ} .118 / 2005$, e não aos valores indevidamente recolhidos antes da vigência da referida lei, conforme o STJ vinha concluindo.

Assim, toda a divergência jurisprudencial que existia sobre o tema ficou definitivamente superada, visto que foi decidido pelo STF, que é o Órgão constitucionalmente investido para dar a última palavra em temas que versem sobre a Constituição. Assim, o próprio Superior Tribunal de Justiça passou a aplicar em seus julgados o entendimento adotado pelo STF, conforme mostrado abaixo: 
TRIBUTÁRIO. EMBARGOS DE DECLARAÇÃO NO AGRAVO REGIMENTALNOAGRAVO EM RECURSO ESPECIAL. CONTRIBUIÇÃO SOCIAL. TRIBUTO SUJEITO ALANÇAMENTO POR HOMOLOGAÇÃO. PRESCRIÇÃO. ARTIGO $4^{\circ}$ DA LC 118/2005. RE N. 566.621/RS. REPERCUSSÃOGERAL. PRAZOPRESCRICIONALQUINQUENAL.AÇÕES AJUIZADAS APÓS A VIGÊNCIA DA LC N. 118/2005. DIREITO INTERTEMPORAL. AÇÃOAJUIZADAEM DATAPOSTERIOR.

$$
\text { (...) }
$$

4. O Supremo Tribunal Federal, ao reconhecer a repercussão geral da matéria no RE 566.621/RS, proclamou que o prazo prescricional de cinco anos, previsto na Lei Complementar n. 118/2005, somente se aplica às ações ajuizadas após 9.6.2005.

5. Na espécie, a ação de repetição de indébito foi ajuizada em 13.1.2010, data posterior à vigência da LC n. 118/2005, sendo aplicável, portanto, o prazo prescricional de cinco anos.

6. Embargos de declaração acolhidos, com efeitos modificativos, para reconhecer a prescrição das parcelas anteriores ao quinquênio do ajuizamento da ação.

(STJ, EDcl no AgRg no AREsp 8.122/RS, Rel. Ministro BENEDITO GONÇALVES, Primeira Turma, julgado em 27/09/2011) (grifado)

Desse modo, nos tributos lançados por homologação, o prazo prescricional de 10 (dez) anos somente poderá ser aplicado nos casos em que o sujeito passivo, concomitantemente, tenha realizado o pagamento e ajuizado a respectiva ação de repetição de indébito, antes do decurso da vacatio legis de 120 dias da LC n $n^{\circ} 118 / 2005$, ou seja, até o dia 08/06/2005.

\section{CONCLUSÃO}

Ante o exposto, conclui-se que a prescrição tributária possui natureza jurídica e campo de atuação próprio que a diferenciam em relação à prescrição civil; sendo tal distinção bem mais visível em determinados pontos como o que versa sobre o termo inicial para a contagem do prazo prescricional que na prescrição civil começa a correr a partir do momento em que há violação ou lesão ao direito do sujeito, enquanto que na prescrição tributaria, somente passa a correr a partir do momento que há a constituição definitiva do crédito tributário.

Também, pode-se concluir que nos tributos sujeitos a lançamentos por homologação, o sujeito passivo se antecipa à Fazenda Pública, entrega ao Fisco a declaração devida, informando o valor que entende devido dos tributos, e 
procede à quitação da exação, aguardando o procedimento homologatório expresso ou tácito.

Verificou-se, também, que o tema prescrição tributária nos tributos sujeitos a homologação pode ser dividido em dois momentos básicos: um anterior a vigência da Lei Complementar 118 e outro posterior a sua vigência; ou seja, após o dia 09 de Fevereiro de 2005.

Por fim, ficou demonstrado, que toda a celeuma jurídica que envolvia o tema prescrição tributária, em tributos sujeitos a homologação, somente ficou superado a partir de 04 de agosto de 2011, oportunidade em que o Supremo Tribunal Federal proferiu decisão, nos autos do Recurso Extraordinário $\mathrm{n}^{\circ}$. 556.621, submetido ao regime de repercussão geral, firmando o entendimento de que o prazo prescricional quinquenal tão somente deve ser aplicado às ações ajuizadas após a vigência da $\mathrm{LC} \mathrm{n}^{\circ}$. 118/2005, e não aos valores indevidamente recolhidos antes da vigência da referida lei, conforme o STJ vinha decidindo.

\section{REFERÊNCIAS}

BRASIL. Congresso Nacional. Constituição Federal Brasileira de 1988.Disponível em: $<$ http://www2.planalto.gov.br $>$. Acesso em:

20 abril de 2012.

BRASIL. Congresso Nacional. Código Civil Brasileiro de 2002.Disponível em: $<$ http://www2.planalto.gov.br $>$. Acesso em: 20 abril de 2012.

BRASIL. Congresso Nacional. Código Tributário Nacional. Disponível em: <http://www2.planalto.gov.br>. Acesso em: 20 abril de 2012.

DANARI, Zelmo. Curso de direito tributário. 8 ed. São Paulo: Atlas,2002.

MARTINS, Sergio Pinto. Manual de direito tributário. 3 ed. São Paulo:Atlas, 2004.

MACHADO, Hugo de Brito. Curso de direito tributário. Decadência elançamento por homologação tácita no artigo 150 do CTN. Disponível 
em: <http://bdjur.stj.gov.br/dspace/handle/2011/1286>.

Acesso em 8 abril 2012.

SUPERIOR TRIBUNAL DE JUSTIÇA. $1^{\text {a }}$ Seção. Embargos deDivergência em Recurso Especial n 262475/DF. Relator: Ministro FranciulliNeto. Decisão unânime. Brasília, 23.4.2003. DJ de 04/08/2003. Disponível em: < https://ww2.stj.jus.br/processo/revistaeletronica/ inteiroteor?num_registro $=200001360728 \&$ data $=4 / 8 / 2003=>$. Acesso em: 07abril 2012.

SUPERIOR TRIBUNAL DE JUSTIÇA. 1 ${ }^{a}$ Turma. Embargos deDeclaração no Agravo Regimental em Recurso Especial no 8.122/ RS.Relator: Ministro Benedito Gonçalves. Decisão unânime.

Brasília,27.09.2011. DJ de 30/09/2011. Disponível em: <http://www.stj.jus.br/ SCON/jurisprudencia/ doc.jsp?livre $=\% 28 \% 22 \mathrm{BENEDITO}+\mathrm{GON} \% \mathrm{C} 7 \mathrm{ALVES} \% 22 \% 29 . \mathrm{min} . \& \mathrm{~d}$ ata $=\% 40 \mathrm{DTDE}+\% 3 \mathrm{E} \% 3 \mathrm{D}+20110920+\mathrm{e}+\% 40 \mathrm{DTDE}+\% 3 \mathrm{C} \% 3 \mathrm{D}+201$ $10930 \& \& b=A C O R \& p=$ true $\& t=\& l=10 \& \mathrm{i}=20=>$. Acesso em: 09 abril 2012.

SUPREMO TRIBUNAL FEDERAL. Tribunal Pleno.

RecursoExtraordinário n ${ }^{\circ}$ 556621/RS. Relator: Ministra Rosa Weber. Decisão pormaioria. Brasília, 04.8.2011. DJ de 18/8/2011. Disponível em:<http:// www.stf.jus.br/portal/jurisprudencia/ listarJurisprudencia.asp?s1=\%28RE $\% 24 \% 2 \mathrm{ESCLA} \% 2 \mathrm{E}+\mathrm{E}+56662$ $1 \% 2 \mathrm{ENUME} \% 2 \mathrm{E} \% 29+\mathrm{OU}+\% 28 \mathrm{RE} \% 2 \mathrm{EACMS} \% 2 \mathrm{E}+\mathrm{ADJ} 2+56662$ 1\%2EACMS\%2E\%29\&base=baseAcordaos=>. Acesso em: 09 abril 2012.

TORRES, Ricardo Logo. Curso de direito financeiro e tributário. 13. ed. Rio de Janeiro: Renovar, 2006.

Recebido em: 2012-10-25 Aprovado para publicação em: 2012-12-01

Como citar: POZZETTI, Valmir César; DA SILVA, Nedson Fernandes Brilhante. A prescrição tributária nos tributos sujeitos a homologação. Scientia Iuris, Londrina, v.16, n.2, p.129-142, dez. 2012. DOI: 10.5433/2178-8189.2012v16n2p129. 